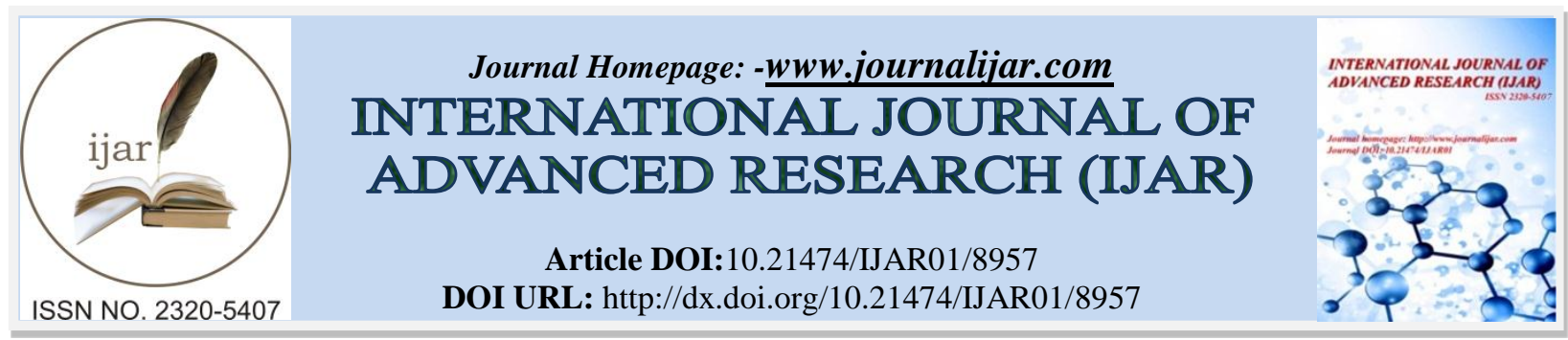

RESEARCH ARTICLE

\title{
ROLE OF THE PHYSICAL ACTIVITY IN THE IMPROVEMENT OF CARDIAC MEASURES AND DECLINING OF COMORBIDITIES.
}

Fayez Saud AL Reshidi, Ahmed Hamed ALJadani, Ahmed Alsolami, Anas Abdulqader Fathuldeen, Mohammed N. Alshammari, Abdullah H. Al Enzi, Hasan A. Alshammari, Mateb M. Albarak, Saud K. Alshammari and Amirah E. Alshammari. Collage of Medicine, University of Hail, Kingdom of Saudi Arabia.

\section{Manuscript Info}

Manuscript History

Received: 22 February 2019

Final Accepted: 24 March 2019

Published: April 2019

Key words:-

Physical activity, blood pressure, cardiovascular disease, stress, Hail region, Saudi Arabia.

\begin{abstract}
Background: Regular physical activity (PA) can prevent many noncommunicable diseases, such as cardiovascular disease (CVD) and diabetes mellitus (DM). The present study aimed to assess the health benefits of physical activities including blood pressure and comorbid conditions.

Methodology: This is a prospective cohort case-control study that recruited 300 Saudi volunteers living in the city of Hail, Northern Saudi Arabia.

Results: Out of 300 participants $155(51.7 \%)$ were males and 145 (48.3\%) were females. There were $111(37 \%)$ participants committed to regular physical activity and the remaining 189(63\%) without a defined commitment to physical activity (Uncommitted). Among 111 persons who claimed a commitment to regular physical activity (committed), $61(55 \%)$ were males and 50(45\%) were females. The majority of committed individuals were at the age group 21-25 years followed by age group 26-30 and 31-35 years representing 32, 30, and 20 persons, respectively. The physical activity was highly practiced at the age range 21-30 years and this was found to be statistically significant $P<0.001$. Conclusion: There is a low prevalence of physical activity in Hail region, particularly among females, which necessitates the suggestion of appropriate awareness programs. Younger and elder populations are in much need to be targeted with PA awareness programs.
\end{abstract}

Copy Right, IJAR, 2019,. All rights reserved.

\section{Introduction:-}

Physical activity (PA) and regular exercise have countless health benefits; almost everybody can feel the benefit from becoming physically more active. A goal of $150 \mathrm{~min} /$ week of moderate-to-vigorous intensity PA was recommended as most international guidelines for beneficial PA. These recommendations indicated that this intensity of PA is the minimum needed to gain health benefit [1].

Different concepts have been employed to define the individual physical activity, such as, "PA," "exercise," and "physical fitness". Though these terms appear to be confusing, repeatedly used interchangeably. The term "PA" is ascribing any bodily movement made by skeletal muscles that consumes energy (measured in kilocalories). There

Corresponding Author:-Fayez Saud AL Reshidi.

Address:-Collage of Medicine, University of Hail, Kingdom of Saudi Arabia. 
are many forms of PA in daily life, such as occupational, sports, conditioning, household, or other activities. Exercise is a type of PA that is planned, structured, and repetitive and has the objective of improvement or maintenance of physical fitness. Physical fitness is a set of qualities that are either health- or skill-related, which can be measured with specific tests [2]. The evidence is overwhelming with risk drops of at least $20 \%-30 \%$ for more than 25 chronic medical conditions and premature mortality. Even higher risk reductions (ie, $\geq 50 \%$ ) are perceived when objective measures of physical fitness are engaged. International PA guidelines usually endorse 150 minutes per week of moderate- to vigorous-intensity PA [3]. Exercises and PA promotion according to public health recommendations for PA enhanced cardiovascular (CV) fitness, muscle strength and PA performance [4].

As exercise is acknowledged to enhance $\mathrm{CV}$ consequences such as angiogenesis and endothelial function, much consideration is being assumed to exercise to recover the number and function of circulating angiogenic cells (CACs). Consequently, there is a rising body of evidence that acute, short-term, and chronic exercise have a beneficial influence on the number and function of diverse subgroups of CACs [5]. Exercise in young adults has been steadily revealed to enhance many characteristics of physiological and psychological health with tremendous realizing of the potential benefits of exercise with the proceeding of age. Precisely, exercise improves cardiovascular, musculoskeletal, and metabolic health through diminutions in oxidative stress, chronic low-grade inflammation and modulating cellular processes within a range of tissues [6].

In spite of well-known evidence that PA is efficient for tumbling the risk of non-communicable diseases, as well as the significance and cost-effectiveness of PA counseling in the primary care setting, few studies have been conducted regarding PA counseling in Saudi Arabia [7]. Thus the present study aimed to assess the health benefits of physical activities including blood pressure and comorbid conditions.

\section{Materials and Methods:-}

This is a prospective cohort case-control study that recruited 300 Saudi volunteers living in the city of Hail, Northern Saudi Arabia. Participants were targeted in different public settings in the city. Participants were randomly selected by simple random method regardless of age, gender, education level or occupation. A purposeful questionnaire was designed and used for obtaining the necessary data. Beside demographical data of the participants, the poll included variables, such as, period of commitment to physical activity, daily duration of physical activity, lifestyle-related factors including: stress factors, energy drinks, coffee consumption, smoking, sleeping hours per day, daily sleeping time; comorbid conditions including: diabetes mellitus (DM), hypertension, chronic kidney disease, and high blood cholesterol.

\section{Study population}

The study population was grouped based on the physical activity levels and divided into two groups: physically active committed group (ascertained as committed) and uncommitted group (ascertained as uncommitted).

"Committed group" was defined as people who were committed to regular physical activity (exercise) for at least 6 months. "Uncommitted group" included those who were not involved in any regular exercise but might be involved in leisure time activities.

\section{Blood pressure and heart rate measurements}

Resting heart rate \& Blood pressure measurements were taken after 5 minutes rest in a seated position in a quiet place. The measurements were evaluated using an oscillometric device (beurer BM58).

\section{Data Analysis}

Statistical Package for Social Sciences (version 23) was used for analysis and to perform the Pearson Chi-square test for statistical significance (P-value). The 95\% confidence level and confidence intervals were used. A p value less than 0.05 was considered statistically significant.

\section{Ethical Consent}

Each participant was asked to sign a written ethical consent during the questionnaire's interview.

\section{Results:-}

This study assessed the benefit of physical activity in 300 volunteers, their ages ranging from 18 to 64 years old with a mean age of 27 years. Out of 300 participants, 155(51.7\%) were males and $145(48.3 \%)$ were females. There were 
111(37\%) participants committed to regular physical activity and the remaining 189(63\%) without a defined commitment to physical activity. Among 111 persons who claimed a commitment to regular physical activity (committed), 61(55\%) were males and 50(45\%) were females. The majority of committed individuals were at the age group 21-25 years followed by age group 26-30 and 31-35 years representing 32, 30, and 20 persons, respectively. The physical activity was highly practiced at the age range 21-30 years and this was found to be statistically significant $\mathrm{P}<0.001$.

The highest levels of physical activities were noticed among higher educated people, graduated and secondary levels representing 82 and 25 persons in this order, as indicated in Table 1, Fig 1.

Table 1:-Physical activity by sex, age, and education

\begin{tabular}{|l|l|l|l|}
\hline Variable & Committed $(\mathbf{n}=\mathbf{1 1 1})$ & Uncommitted $(\mathbf{n}=\mathbf{1 8 9})$ & Total $(\mathbf{n}=\mathbf{3 0 0})$ \\
\hline Sex & & & \\
\hline Males & 61 & 94 & 155 \\
\hline Females & 50 & 95 & 145 \\
\hline Total & 111 & 189 & 300 \\
\hline Age & & & \\
\hline$\leq 20$ years & 10 & 31 & 41 \\
\hline $21-25$ & 32 & 85 & 117 \\
\hline $26-30$ & 30 & 32 & 62 \\
\hline $31-35$ & 20 & 18 & 38 \\
\hline $36-40$ & 13 & 10 & 23 \\
\hline$\geq 41$ & 6 & 13 & 19 \\
\hline Education & & & \\
\hline Illiterate & 1 & 1 & 2 \\
\hline Basic & 3 & 3 & 6 \\
\hline Secondary & 25 & 63 & 88 \\
\hline graduated & 82 & 122 & 204 \\
\hline
\end{tabular}

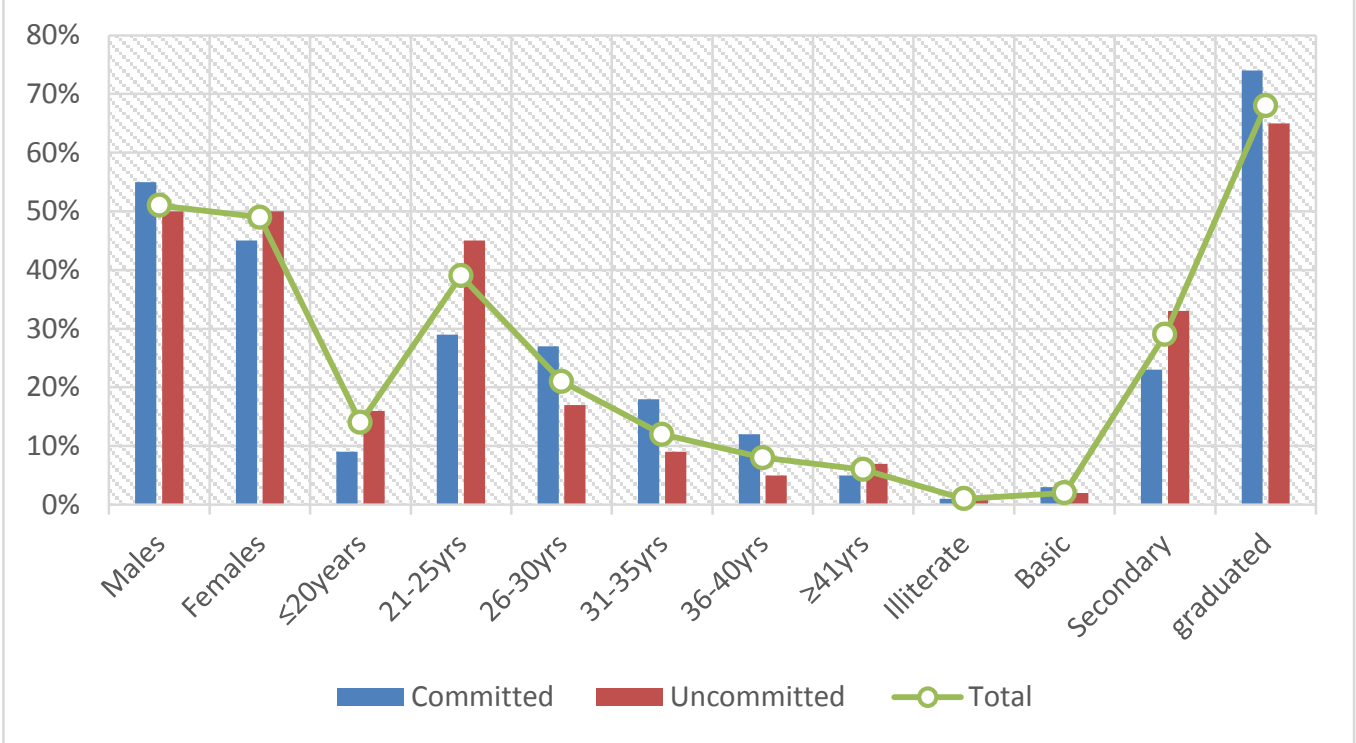

Figure 1:-Physical activity by sex, age, and education

Out of the 111 committed persons, 37, 26, and 20 were found to practice physical activity for periods of 13-24 months, 6 months and more than 25 months, correspondently, as shown in Fig 2. About 68, and 41 persons practice physical activity for 21-30 and 11-20 days per month, as shown in Fig 3. 


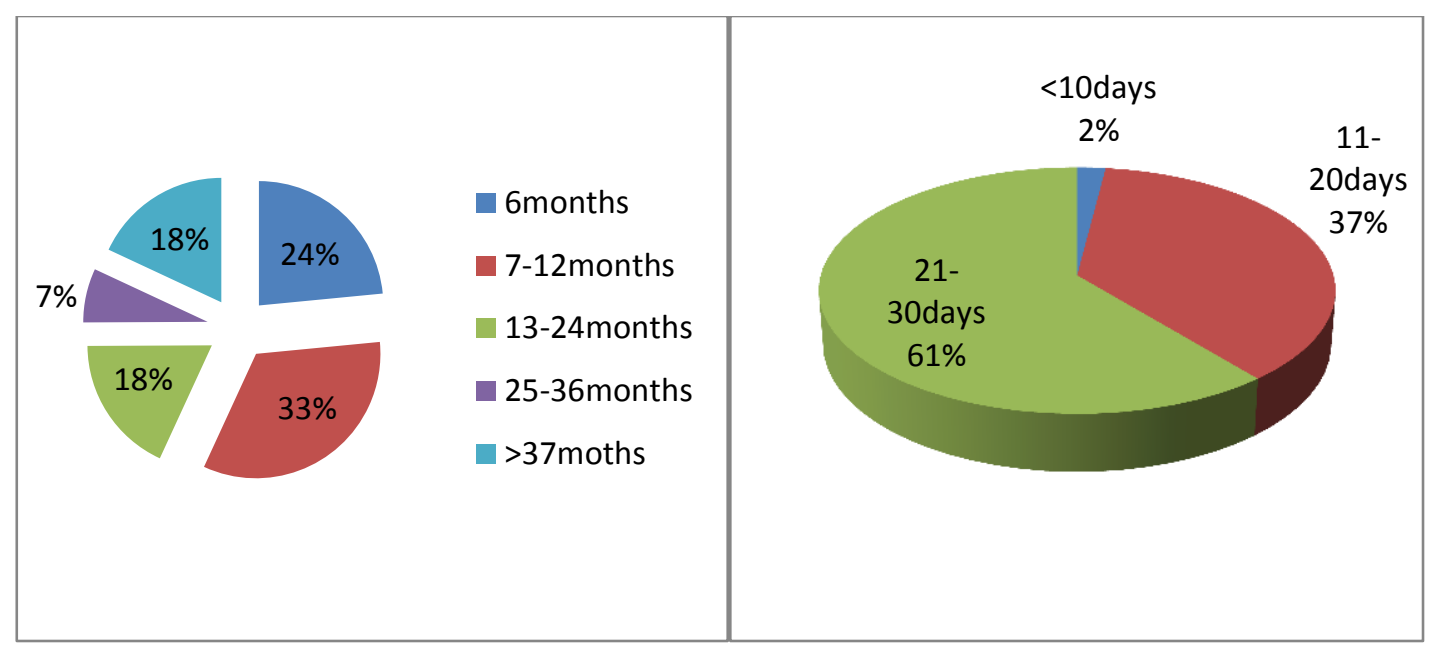

Figure 2:-Physical activity by the period of commitment. Figure 3. Days of activity per month.

Most study subjects use to practice physical activity for $<60$ minutes per day, followed by 91-120 minutes constituting 37 and 36 subjects in this order as shown in Fig 4.

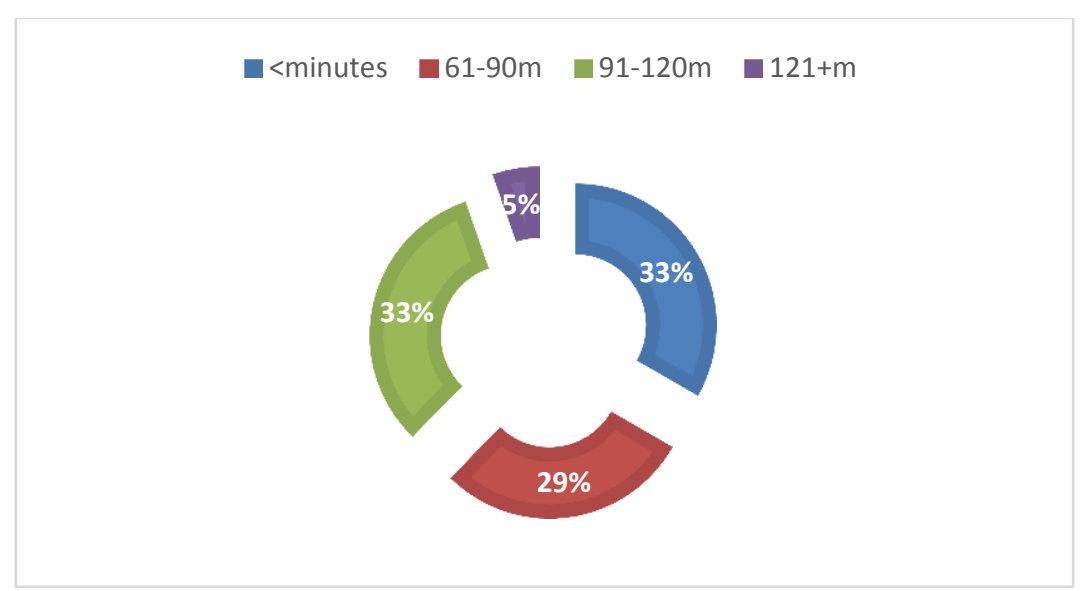

Figure 4:-Duration (minutes) of physical activity per day

With regard to the cardiac systolic efficiency, 136/300(45.3\%) were found with optimal systolic blood pressure (50/111(45\%) committed and 86/189(45.5\%) were uncommitted). Hypertension was indicated in 33/300(11\%) participants $(9 / 111(8 \%)$ committed and 24/189(12.7\%) were uncommitted). With regard to the cardiac diastolic efficiency, 112/300(37.3\%) were found with optimal systolic blood pressure (43/111(39\%) committed and $69 / 189(36.5 \%)$ were uncommitted). Hypertension was indicated in 56/300(18.7\%) participants $(17 / 111(15.3 \%)$ committed and 39/189(20.6\%) were uncommitted). About 264/300(88\%) of the study subjects were found with heart rates between 60 and 100 per minute. Rate levels over 100 were identified among 29/300(10\%) (4/111(3.6\%) were committed and 25/189(13.2\%) were uncommitted), as indicated in table 2, Fig 5.

Table 2:-Heart efficiency by physical activity

\begin{tabular}{|l|l|l|l|}
\hline Variable & Committed $(\mathbf{n = 1 1 1})$ & Uncommitted $(\mathbf{n}=189)$ & Total(n=300) \\
\hline Systolic blood pressure & 50 & & \\
\hline Optimal & 31 & 86 & 136 \\
\hline Normal & 21 & 48 & 79 \\
\hline High-normal & 9 & 31 & 52 \\
\hline hypertensive & 24 & 33 \\
\hline Diastolic blood pressure & 43 & & \\
\hline Optimal & 69 & 112 \\
\hline
\end{tabular}




\begin{tabular}{|l|l|l|l|}
\hline Normal & 19 & 46 & 65 \\
\hline High-normal & 32 & 35 & 67 \\
\hline hypertensive & 17 & 39 & 56 \\
\hline Heart rate & & & \\
\hline Low & 2 & 5 & 7 \\
\hline Normal & 105 & 159 & 264 \\
\hline High & 4 & 25 & 29 \\
\hline
\end{tabular}

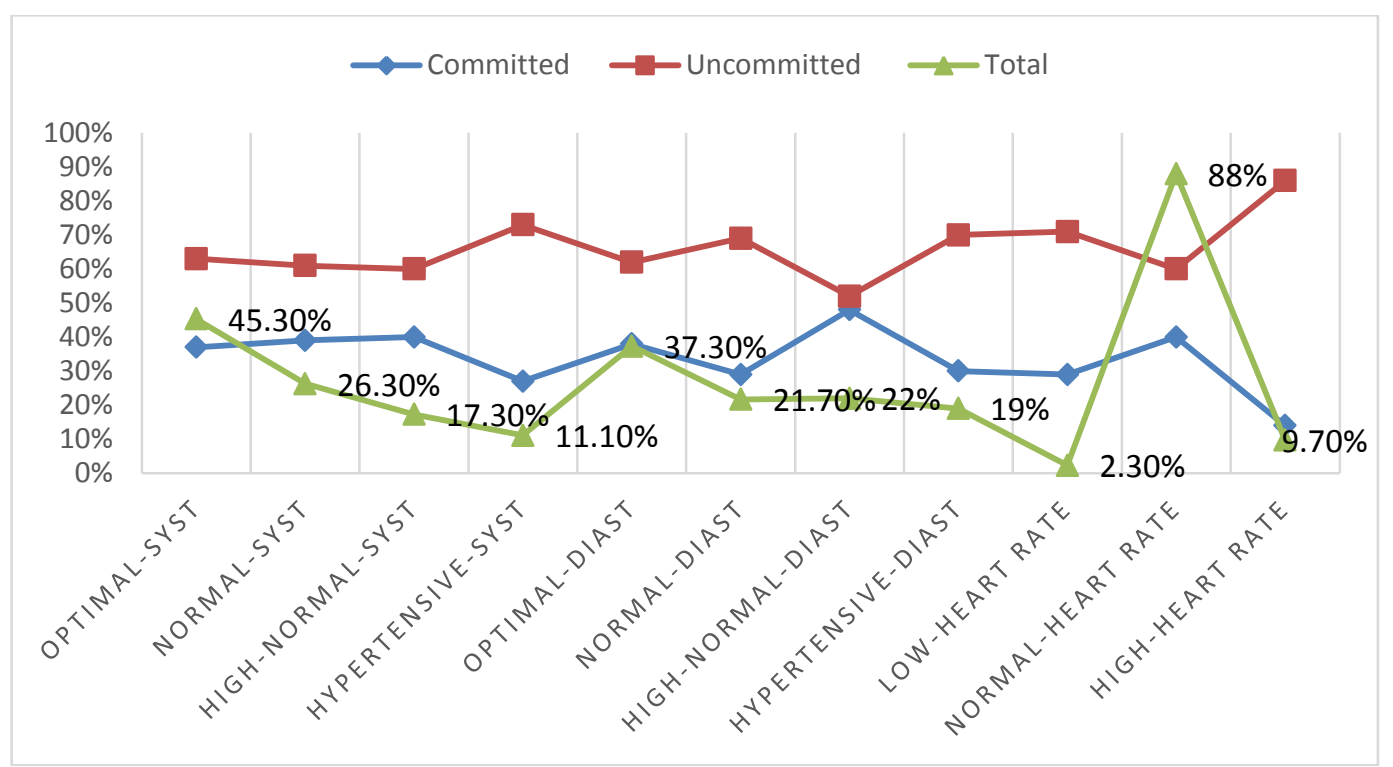

Figure 5:-Heart efficiency by physical activity

Table 3, summarizing physical activity status by lifestyle cardiovascular related factors. Stress was commonly encountered at work 79/300(26.3\%) (31/111(28\%) were committed and 48/189(25.4\%) were uncommitted). Within entire groups; stress factors were more common among the committed group. Energy drinks consumption was noted among $15 / 111(13.5 \%)$ of the committed compared to 49/189(26\%) of the uncommitted. Coffee consumption was noted among $97 / 111(87.5 \%)$ of the committed compared to $154 / 189(81.5 \%)$ of the uncommitted. Smoking habit was noted among $31 / 111(28 \%)$ of the committed compared to $28 / 189(15 \%)$ of the uncommitted. Around $12 / 111(11 \%)$ of the committed used to sleep for less than 6 hours per day compared to 27/189(14.3\%) of the uncommitted. Late sleeping habit after 12:00 PM was identified among 53/111(47.7\%) of the committed compared to 102/189(54\%) of the uncommitted, as indicated in Table 3.

As it was shown in Fig 6, the frequencies of comorbid conditions were lower in the committed group compared to the uncommitted group

Table 3:-Physical activity by cardiovascular related factors

\begin{tabular}{|l|l|l|l|}
\hline Variable & Committed $(\mathbf{n = 1 1 1})$ & Uncommitted $(\mathbf{n = 1 8 9})$ & Total $(\mathbf{n = 3 0 0})$ \\
\hline Stress factors & & & \\
\hline At work & 31 & 48 & 79 \\
\hline At home & 25 & 12 & 37 \\
\hline At community & 9 & 18 & 27 \\
\hline More than 2 factors & 16 & 9 & 25 \\
\hline Others & 0 & 2 & 2 \\
\hline No stress & 30 & 100 & 130 \\
\hline Energy drinks & & & \\
\hline Yes & 15 & 49 & 64 \\
\hline No & 96 & 140 & 236 \\
\hline Coffee & & & \\
\hline
\end{tabular}




\begin{tabular}{|l|l|l|l|}
\hline Yes & 97 & 154 & 251 \\
\hline No & 14 & 35 & 49 \\
\hline Smoking & & & \\
\hline Yes & 31 & 28 & 59 \\
\hline No & 80 & 161 & 241 \\
\hline Sleeping hours & & & \\
\hline$>6$ hours & 12 & 27 & 39 \\
\hline $6-8$ & 81 & 121 & 202 \\
\hline$>8$ hours & 18 & 41 & 59 \\
\hline Sleeping time & & & \\
\hline Before 10:00PM & 33 & 25 & 58 \\
\hline Before 12:00 AM & 25 & 62 & 87 \\
\hline After 12:00 AM & 53 & 102 & 155 \\
\hline
\end{tabular}

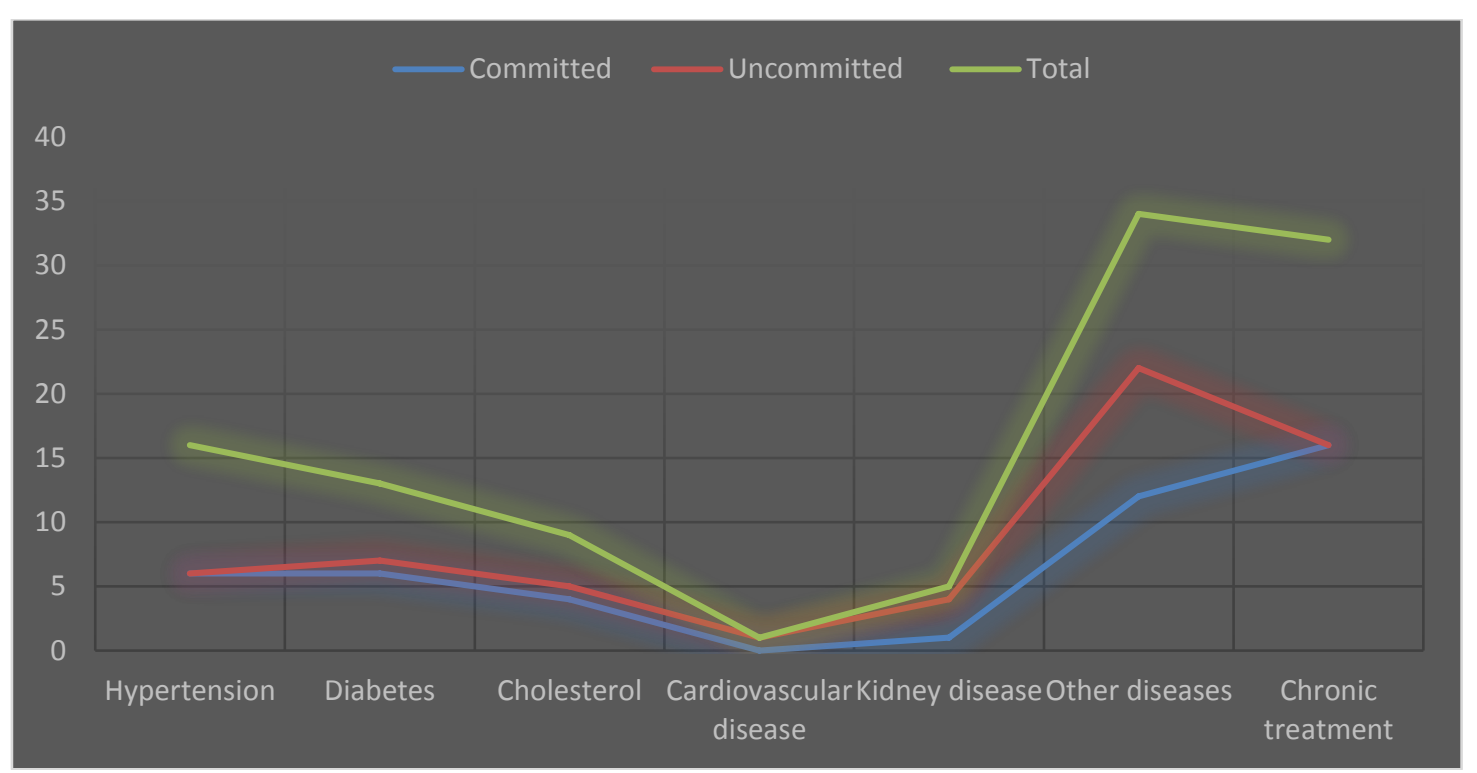

Figure 6:-Physical activity by comorbid conditions

\section{Discussion:-}

With the increase in the sedentary lifestyle in recent years, many diseases including DM, hypertension, and CVD are becoming highly prevalent among the physically inactive population. Accordingly, the current study aimed to assess the value of physical activity in enhancing cardiac parameters, as well as, decreasing the comorbidities such as DM, hypertension etc.

The present study indicated a prevalence of physical activity of 37\% among the studied population, which is a very low level. In Study from Saudi Arabia to determine prevalence and pattern of leisure time physical activity among adult Saudis aged $18-65$ years, only $21.0 \%$ of the included sample were considered as being sufficiently active and $10.4 \%$ were in the high active category with beneficial health effects [8]. Compared to the results of this study, these findings may indicate the improvement in PA status in recent years in Saudi Arabia, which necessitate the importance of awareness in such population. Another Saudi study involved the extent of physical activity among physicians and assessing the likelihood of counseling the patients on physical activities. About $65.2 \%$ of respondents were doing moderate to vigorous physical exercise and $34.8 \%$ of them were physically inactive [9].

In the present study, males were more active than females and the majority of the active persons were found at the age range 21 to 30 years. These findings call for educational work in children, adolescents, and older people. Moreover, the highest levels of physical activities were noticed among higher educated people. 
Most of the study subjects were found to practice physical activity for periods of less than one year. However, this period might not be enough to produce apparent benefits, particularly with low intensity. Moreover, most study subjects use to practice physical activity for $<60$ minutes per day. These findings may emphasize the narrow gaps among the studied two groups (committed and uncommitted).

With regard to the cardiac parameters (systolic, diastolic pressure, and heartbeat), showed no differences between the two investigated groups. These might be attributed to the short period and low activity intensity, which was indicated for the majority of studied persons. Intended outcomes may require strict inclusion and exclusion criteria in term of duration and intensity of physical activity. Fixing 6 months as inclusion period regardless of PA intensity and cycle extension might be a limitation in the present study.

As lifestyle-related factors such as stress [10], smoking [11], caffeine [12], and sleeping quality [13] can produce cardiovascular changes, the present study considered them and revealed no statistically significant. Although the random distribution of these factors was relatively similar amongst both groups (committed and uncommitted), there were no apparent variations.

In the present study, the overall frequencies of comorbid conditions were lower among active individuals (committed) compared to relatively inactive persons (uncommitted). It was reported that Leisure-time physical activity may be considered as an efficient and inexpensive non-pharmacological tool for DM treatment [14]. Exercise is an effective strategy for reducing blood pressure in the general population; however, it is not known whether exercise would have a comparable benefit in people with moderate to advanced chronic kidney disease and hypertension [15]. Recent studies showed that exercise and lifestyle risk factor management are critical for the secondary prevention of cardiovascular disease but are poorly adhered to [16]. Elevated levels of highdensity lipoprotein cholesterol (HDL-C) have been associated with a decreased risk of coronary heart disease (CHD). An active lifestyle is necessary in order to improve lipid HDL-C, including (but not limited to) physical exercise [17].

\section{In conclusion:-}

there is a low prevalence of physical activity in Saudi Arabia, particularly among females, which necessitates the suggestion of appropriate awareness programs. Younger and elder populations are in much need to be targeted with PA awareness programs. Further studies with strict inclusion and exclusion criterion needed to assess the health benefits variations between active and inactive individuals.

\section{Acknowledgment:-}

Authors would like to thank Elaf Faris Al-Tebainawi, Fahad Ali Aldamadi, Lamyaa Nahar Alshammari as they participated as data collectors in this study.

\section{References:-}

1. Warburton DER, Bredin SSD. Health benefits of physical activity: a systematic review of current systematic reviews. Curr Opin Cardiol. 2017 Sep;32(5):541-556. doi: 10.1097/HCO.0000000000000437.

2. Caspersen CJ, Powell KE, Christenson GM. Physical activity, exercise, and physical fitness: definitions and distinctions for health-related research. Public Health Rep. 1985;100(2):126-31.

3. Warburton DE, Bredin SS. Reflections on Physical Activity and Health: What Should We Recommend? Can J Cardiol. 2016 Apr;32(4):495-504. doi: 10.1016/j.cjca.2016.01.024.

4. Rausch Osthoff AK, Juhl CB, Knittle K, et al. Effects of exercise and physical activity promotion: metaanalysis informing the 2018 EULAR recommendations for physical activity in people with rheumatoid arthritis, spondyloarthritis and hip/knee osteoarthritis. RMD Open. 2018;4(2):e000713. Published 2018 Dec 4. doi:10.1136/rmdopen-2018-000713

5. Landers-Ramos RQ, Sapp RM, Shill DD, Hagberg JM, Prior SJ. Exercise and Cardiovascular Progenitor Cells. Compr Physiol. 2019 Mar 14;9(2):767-797. doi: 10.1002/cphy.c180030.

6. Ross M, Lithgow H, Hayes L, Florida-James G. Potential Cellular and Biochemical Mechanisms of Exercise and Physical Activity on the Ageing Process. Subcell Biochem. 2019;91:311-338. doi: 10.1007/978-981-13-3681-2_12.

7. Alahmed Z, Lobelo F. Physical activity promotion in Saudi Arabia: A critical role for clinicians and the health care system. J Epidemiol Glob Health. 2018 Mar;7 Suppl 1:S7-S15. 
8. Amin TT, Al Khoudair AS, Al Harbi MA, Al Ali AR. Leisure time physical activity in Saudi Arabia: prevalence, pattern and determining factors. Asian Pac J Cancer Prev. 2012;13(1):351-60. doi: 10.1016/j.jegh.2017.10.005.

9. Banday AH, Want FA, Alris FF, Alrayes MF, Alenzi MJ. A Cross-sectional Study on the Prevalence of Physical Activity Among Primary Health Care Physicians in Aljouf Region of Saudi Arabia. Mater Sociomed. 2015;27(4):263-6.

10. Gianaros PJ, Jennings JR. Host in the machine: A neurobiological perspective on psychological stress and cardiovascular disease. Am Psychol. 2018 Nov;73(8):1031-1044. doi: 10.1037/amp0000232.

11. Ng M, Freeman MK, Fleming TD, et al. Smoking prevalence and cigarette consumption in 187 countries, $1980-$ 2012. JAMA 2014;311:183-92.

12. Zhou A, Hyppönen E. Long-term coffee consumption, caffeine metabolism genetics, and risk of cardiovascular disease: a prospective analysis of up to 347,077 individuals and 8368 cases. Am J Clin Nutr. 2019 Mar 1;109(3):509-516. doi: 10.1093/ajcn/nqy297.

13. Chair SY, Wang Q, Cheng HY, et al. Relationship between sleep quality and cardiovascular disease risk in Chinese post-menopausal women. BMC Womens Health. 2017;17(1):79. Published 2017 Sep 11. doi:10.1186/s12905-017-0436-5.

14. Sadarangani KP, Von Oetinger A, Soto Isla N, Martínez-Gómez D. Leisure time physical activity is associated with better metabolic control in adults with type 1 and type 2 diabetes mellitus: A cross-sectional study from two public hospitals in Chile. Prim Care Diabetes. 2019 Feb 19. pii: S1751-9918(18)30217-1. doi: 10.1016/j.pcd.2019.01.009.

15. Thompson S, Wiebe N, Gyenes G, Davies R, Radhakrishnan J, Graham M. Physical Activity In Renal Disease (PAIRED) and the effect on hypertension: study protocol for a randomized controlled trial. Trials. 2019;20(1):109. Published 2019 Feb 8. doi:10.1186/s13063-019-3235-5.

16. Maddison R, Rawstorn JC, Shariful Islam SM, et al. mHealth Interventions for Exercise and Risk Factor Modification in Cardiovascular Disease. Exerc Sport Sci Rev. 2019;47(2):86-90.

17. Nassef Y, Lee KJ, Nfor ON, Tantoh DM, Chou MC, Liaw YP. The Impact of Aerobic Exercise and Badminton on HDL Cholesterol Levels in Adult Taiwanese. Nutrients. 2019 Feb 28;11(3). pii: E515. doi: 10.3390/nu11030515. 